\title{
APPLYING THE ANALYTIC HIERARCHY PROCESS TO OIL SANDS ENVIRONMENTAL COMPLIANCE RISK MANAGEMENT
}

\author{
Izak J. Roux III, M. Eng. P. Eng. \\ E-mail:izak.roux@waldenu.edu
}

\begin{abstract}
Oil companies in Alberta, Canada, have spent more than $\$ 15$ billion in 2013 on new oil-sands projects. There is demonstrable deficiency in the uniformity and understanding of environmental legislation requirements, which can lead to environmental damage. The purpose of this quantitative study is to develop a prioritized list of environmental regulatory compliance risk factors and mitigation strategies for oil-sands projects using the Analytic Hierarchy Process (AHP). The multicriteria decision-making process using expert input is the basis for the study's theoretical foundation. The quantitative descriptive design consists of 3 phases: (a) the identification of the potential environmental compliance risk factors and mitigation strategies using the Alberta Energy Regulator (ERCB) database; (b) the formation and administration of a pilot study followed by a specialized survey on a sample of 15 industry-specific subject matter experts (SMEs) to provide their individual pairwise priorities among the identified risk factors and mitigations strategies; and (c) the application of the AHP, using SuperDecisions, on the collected sample to rank each of the risk factors and mitigation strategies. Enabling the Alberta oil companies' leaders to gain additional legislative and public trust through demonstrating improvements to their environmental risk management practices can make social-economic change possible. Knowing not only the environmental risk factors but also understanding the ranking of these factors will help oil companies completing sustainable oil sands projects in compliance with the local regulator's requirements.
\end{abstract}

Keyword: AHP, Alberta, oil sands, environment, regulatory compliance, risk factors 